Island Studies Journal, Vol. 3, No. 2, 2008, pp. 175-198

\title{
Branding From Above: Generic Cultural Branding in Shetland and other Islands
}

\author{
Adam Grydehøj \\ The Elphinstone Institute \\ The University of Aberdeen \\ Scotland, United Kingdom \\ frunco1@hotmail.com
}

\begin{abstract}
This paper considers the development of a generic cultural brand for islands. In 2002, Shetland's local government and the Corporate Edge consultancy developed a modernized, internationally-oriented Shetland brand. This official brand conflicts with Shetlanders' traditional, locally-oriented identity concept, which has impeded the brand's success. With emphasis on printed tourism marketing materials, Shetland's experience is compared with those of other European islands. This comparison highlights a predominance of cultural island brands emphasizing modernity and old-fashionedness. Finally, this paper looks at problems with top-down place branding and suggests that those involved in centralized place branding processes take local identity into account.
\end{abstract}

Keywords: branding, identity, islands, marketing, Shetland, tourism

(C) 2008 - Institute of Island Studies, University of Prince Edward Island, Canada.

\section{Introduction}

Place branding as a professional practice is recognizable in history, with concerted, commercial efforts at branding destinations for tourism going back at least to Thomas Cook's mid-19 ${ }^{\text {th }}$-Century revolution of organized travel (Chambers, 2000: 13). In contrast, the study of place branding as a distinct discipline is a relatively-new development. At its heart, place branding - both academically and practically - is an interdisciplinary field (Jaffe \& Nebenzahl, 2006: 9): Its situation is similar to that of the field of island studies, which is likewise undergoing conscious disciplinary delineation and which likewise aims for a holistic approach to its subject matter (Depraetere, 2008).

This paper will use the place-branding process that has been undertaken in the Shetland archipelago as a case study to examine the relationship between marketing, marketers, and the product being marketed. It is not just that marketers use marketing to disseminate a message about a product. The complex and evolving nature of the product (the place) itself and the marketers' frequent personal identification of themselves as part of the product means that the very process of place branding has the dual potential to inform policy makers and to intensify their prejudices. Even though the Shetland place branding process was conceived of as a marketing tool, one of its main objectives ended up being to change the nature of the product (that is, Shetland and Shetland society). This paper will show how miscommunication about what branding should entail has been detrimental to the building 


\section{A. Grydehøj}

of a vital 'Shetland brand'. We will also see that the repercussions of this failure have extended beyond the realm of single-sector advertising campaigns.

This paper will furthermore argue that place branding exercises run the risk of focusing too much on the perceived desires of consumers, thereby losing sight of the actual places being branded. Every place has a brand, regardless of whether or not it has undergone a conscious branding process (Jaffe \& Nebenzahl, 2006: 9-10). In the case of Shetland, this pre-existing, traditional, popular brand (or conception of Shetland identity) is in a problematic relationship with the new, modernized, official brand conceived and implemented by marketing bodies and the local government. Nevertheless, those responsible for the official brand have tended to ignore the popular brand or, worse, have worked to counteract it.

Finally, this article will compare the Shetland experience with similar efforts to brand islands elsewhere and will speculate as to what the ideal relationships between identity and branding - and between place product and marketing - should be.

That said, it is not my intention to castigate place branding researchers and practitioners, and I am aware that not all such experts will take kindly to a disciplinary outsider meddling in their field. Instead, this paper will offer a folkloric analysis of where place branding practice has, perhaps, veered off course. It may be that this analysis, seen from the perspective of a methodologically-alien field, will differ from those of many place branding academics, and in this sense, the paper aims to add another tool to the practitioners' box while expanding the awareness of academics in a variety of fields about the breadth of issues that come into play when considering place branding.

\section{Ethnography and Methodology}

The work of most folklorists and anthropologists is rooted in the ethnographic method. While it is possible to write about folklore without having conducted ethnographic fieldwork, it is such fieldwork that provides folklore's primary sources. Thus, when Alan Dundes splits the folkloric process into two actions (identification and interpretation), he does so in order to emphasize the primary importance of the objective ethnographic method as a means of contextualizing collected folklore 'texts'; folklore may need subjective, ethnological interpretation to be relevant, but subjective interpretation in itself is literary criticism, not folklore (Dundes, 1965). In the late- $19^{\text {th }}$ and early- $20^{\text {th }}$ Centuries, many academic folklorists strove, in line with the field's origins in philology, for the establishment of their discipline as a science. This attempt was unsuccessful, and folklore is still popularly confused with non-scholarly antiquarianism and popular historiography to an extent to which folklore's sister discipline, anthropology, is not. Regardless of whether, at the present time, folklore should still aim for scientific status, ethnographic fieldwork can be said to yield scientifically falsifiable results; the trouble is, the sorts of results that this methodology yields are not always easy for scholars in other fields to interpret. 
Although this paper is interdisciplinary in scope, the research that forms its basis is ethnographic fieldwork in Shetland. Primarily over the course of a seven-month period in 2007, I lived in Shetland and conducted recorded interviews with 75 local residents. Although the concept of fieldwork includes everyday interactions within the social sphere, the 'texts' that form the backdrop for this article are mainly my formal interviews. I interviewed individuals from a wide range of social, geographical, gender, age, and educational backgrounds within the islands, including both Shetland natives and incomers. I placed special - though by no means exclusive - emphasis on people who I was already aware had a special interest in Shetland identity, the subject that I had set out to study. The one caveat here is that the vast majority of my contributors were adults, and most were over the age of 40. This is not as inhibiting a factor as it may appear since the younger age brackets are of less relevance to a study of present-day expression of Shetland identity, particularly by conscious cultural actors, than are the older age brackets, whose opinions dominate the local media and the public sphere as a whole.

As is so often the case when conducting ethnographic fieldwork, my list of contributors grew somewhat organically, with one contributor suggesting another and so on. Very few of these contributors are named or quoted directly in this paper as to do so would change the focus of this article entirely. It is necessary to keep in mind, however, that these interviews produced the results upon which I have based my conclusions on Shetlanders' concepts of local identity.

All but a handful of my formal interviews were based around a set of questions to which I requested answers. Nevertheless, an ethnographic interview is not the same as a personally-administered questionnaire: Even though I was generally able to work my entire set of questions into the interviews, the interviews' discussion format precludes strict regularization of questions. Thus, wording of questions varies; in many cases, a contributor's response to one question from my list would provide the answers to other related questions without prompting. Indeed, one of the advantages to ethnographic methodology as opposed to some questionnaires, surveys, and focus groups often carried out within the social sciences is that a skilled interviewer can elicit many answers without prompting, thereby avoiding responses given simply on the basis of the contributor answering according to the perceived desired response of the questioner. On a related note, ethnographic interviews permit an excellent understanding of context, at least for the interviewer personally. They provide knowledge of the contributors' personal situations, modes of speaking, and other aspects that come through very unclearly in questionnaires, surveys, and focus groups. Additionally, the ability to speak about research questions as part of a relatively-natural conversation means that one can follow up on hints from contributors and that digressions can take place, revealing significant issues that were not known to the researcher in advance. The relevance of many of these points will become clear below: In the Shetland branding process, a limited arsenal of research techniques meant that those in charge of the islands' branding process simply never became aware of a number of major flaws in their assumptions.

This is not to say that ethnographic fieldwork is a cure-all methodology for every type of social and cultural research. The most severe limitation of the ethnographic method 
involves sample sizes. In the case of my Shetland fieldwork, my 75 interviews amount to about 170 hours of recorded speech, and probably a similar amount of time was spent in merely travelling to and from contributors' houses. It takes, on average, six through eight hours to transcribe an hour's worth of recorded speech, meaning that, were I to completely transcribe my interviews, I would be undertaking an additional 1000-or-so hours of work. Were this sort of timescale permitted to a researcher working with surveys and questionnaires, it would probably be possible to canvass the entire population of Shetland, not just 75 individuals. Obviously, a sample size of 75 does not allow for useful statistical rendering of results. Thus, any statement that I can make about Shetlanders' conceptions of Shetland identity, at the end of my fieldwork process, will inevitably be a generalization. This is a useful point to remember when reading this article, which deals mainly with the most prevalent self-conceptions present in Shetland.

Related to this is the issue that, while any single ethnographic text is scientifically falsifiable, this is not true of the interpretation of mass results. Interpretation of fieldwork results is highly subjective, and even if another researcher wanted to go as far as to attempt to reproduce a study's ethnographic component, there are too many variables to make this possible (Salamone, 1979: 47). One of the great advantages of, say, surveys is that the researcher has complete control over the phrasing of questions, thus reducing variables.

There are inadequacies and strengths to all forms of social and cultural research (Fry et al., 1981). My recommendation as regards studying groups that number more than a few dozen individuals, therefore, is for an integrated approach that combines ethnographic fieldwork with the more controlled and statistically-applicable research techniques. There is an implicit criticism here of current practice in place branding; one that will be made explicit below. However, this criticism applies equally well to folklorists and cultural anthropologists, who have a tendency to rely exclusively on ethnographic methodology. The following study, although dealing with the standardization of insular place branding processes, will include an underlying argument for greater diversity of research techniques and will use place branding as an example of what can go wrong when practicallyapplicable research veers too far in one methodological direction.

\section{Overview of Shetland's History}

In order to understand how Shetland's traditional, popular brand and its modernized, official brand developed, it is first necessary to undertake an overview of the islands' history.

The Shetland Islands (Shetland) constitute a North Sea archipelago nearly equidistant from Bergen in Norway and Aberdeen in Scotland. For our purposes, the islands' history commences at the start of the Viking $\mathrm{Age}^{1}$, around $790 \mathrm{AD}$, when Norwegian pirates began arriving in Orkney and Shetland, probably using the Northern Isles as staging grounds for raids on Scottish and Irish monasteries. The incoming pagan warriors

\footnotetext{
${ }^{1}$ In this paper, 'Viking' is analogous with 'Old Norse', as most Shetlanders understand the term.
} 
encountered an indigenous population of Christian Picts. It is unclear whether these natives were forced to emigrate, assimilated into the growing Norse population, or exterminated. In any case, by the start of Shetland's recorded history, the Northern Isles possessed a purely-Norse culture. The Norwegian settlement represented a societal fresh start for Orkney and Shetland (Crawford, 1987: 40-41, 101).

Orkney and Shetland were integrated into the Norwegian state in about 875, and the resultant earldom became one of the strongest and most autonomous administrative units in Norway's empire, at various times holding sway over Northern Scotland and the Western Isles. The islands remained solidly Scandinavian until the mid- $13{ }^{\text {th }}$ Century, when Norway's interest in its Western holdings began to decrease, gradually giving way to Scottish influences (Wiggen, 2002: 20-21). Shetland finally passed over to Scotland in 1469 , and during the following four centuries, the archipelago's fortunes declined, partially as a result of the greed of its ruling class of large-scale - and largely-Scottish landowners.

In the late- $19^{\text {th }}$ Century, Shetlanders embraced romantic notions of their Viking heritage and began idealizing the Old Norse while demonizing the Scots. Notably, Up-Helly-Aa, a fire festival that had developed in the mid-1800s in Lerwick, Shetland's largest town, gradually transformed into a Viking fire festival, complete with the burning of a replica Norse longship and a squad of men dressed as pagan warriors. Shetland was reclaiming or some might say, re-inventing - its history from Scotland (Cohen, 1983).

\section{The Oil Era}

Shetlanders were ambivalent about the late-1960s discovery of North Sea oil and the subsequent plans to build an oil terminal in Shetland. Although these developments promised economic and infrastructural improvements, there was concern that Shetland culture would be put at risk by incoming oil workers and oil money (e.g. Bartmann, 2000: 41, 43-44). Shetland turned out, however, to be blessed with some canny political operators, who secured exceptional jurisdictional capacity for the local government. These additional powers led to the Shetland Islands Council (hereafter, the SIC) receiving substantial payments from the oil industry, profits that were saved up in trust funds and have been used to promote local enterprise and development (Shetland Islands Council, 2007a). Although these trusts are theoretically independent charitable organizations, in reality, they permit the SIC to fund initiatives by proxy, circumventing United Kingdom (UK) and European Union (EU) regulations placed on local government transactions. Although the oil industry now plays a reduced role in Shetland's economy, the islands' 22,000 residents are still as well off, if not better off, than the average UK citizen (Shetland Local Economic Forum, 2002: 5).

Far from destroying Shetland's traditional culture, the sudden economic boom brought about by the oil era has preserved it better than any gradual transition into wealth could ever have. The trusts subsidize numerous books, CDs, and even a periodical on Shetland culture. Furthermore, just to give one example, the Shetland Amenity Trust employs a full- 
time placename researcher, something that not even most major universities can claim, much less most comparably-sized island communities. Meanwhile, the trusts have been responsible for a number of large-scale cultural initiatives. In 2007, the Shetland Amenity Trust opened an impressive new Shetland Museum and Archives at a cost of $€ 14.7$ million, and the Shetland Arts Trust has recently received the go-ahead to construct a $€ 11.8$-million cinema and music venue.

\section{Branding for Economic Development}

In 2002, the Shetland Local Economic Forum produced the 'Shetland 2012' economic strategy document that aimed "to set a course for economic development in Shetland" over the following ten years. This had been preceded by the Scottish Executive's publication of a number of strategic planning documents, including 'A Smart, Successful Scotland', which had been followed by regional-level strategy documents, such as 'A Smart, Successful Highlands and Islands' (Shetland Local Economic Forum, 2002: 3). Seen in context, 'Shetland 2012' represents the trickle down of long-term perspective approaches to economic management, adjusted to scale. The SIC's ability to influence economic development is strengthened by its large role in Shetland: Around $9.5 \%$ of the population works directly for the SIC, a far-higher council employment rate than elsewhere in Scotland (Reference Economic Consultants, 2006: 35), and the SIC accounts for about $36 \%$ of the value of the Shetland economy (Shetland Islands Council, 2007b: 13).

The stance taken in 'Shetland 2012' is based on the assumption that the oil industry will cease providing significant revenue for Shetland within one generation and that there is therefore:

"[A]need to rethink radically our approach to economic development ... [so that] ... Shetland can continue to have a prosperous economic future" (Shetland Local Economic Forum, 2002: 3).

The document's authors suggest that improvement of Shetland's brand has a role to play in an integrated strategy to benefit not only the tourism industry but also to provide value added to primary and manufacturing sectors like fish farming, fish processing, and knitwear production (Economic Development Unit, 2008: 1-2). This would combat what a 2000 SIC investigation had characterized as "a 'scattered gun' approach being taken to marketing issues in general, both at individual business and at a strategic, Shetland level" (Henderson, 2005: ch. 3).

\section{The Branding Process}

In January 2002, the SIC hired Corporate Edge, a London and Bahrain based branding consultancy, to help develop the Shetland brand. This contract would turn out to be worth $€ 160,000$. Corporate Edge began its work by undertaking "wide consultation with key people in Shetland." Later, the consultants conducted focus groups of Shetlanders to gauge 
interest in brand development and receive "reactions to the idea of establishing an overall quality mark for Shetland, with accompanying quality control mechanisms" (Lodge, 2003: 3). The consultants' research on the ground consisted primarily of discussing branding prospects with a relatively-small circle of individuals who had the expertise necessary to respond to the idea of an administered quality mark for Shetland products. Which is to say, Corporate Edge mostly drew its data from people who, by nature of their own positions and training, were likely to agree with Corporate Edge's strategy from the start.

The implications become clear when reading Corporate Edge's June 2003 report to the SIC. The document states that the interviewees and focus groups possess "a strong feeling that Shetland needs to reclaim its brand," which is hardly the sort of feeling one would expect from the typical Shetlander. Nevertheless, on the basis of its findings, the consultants conclude that the objective must be "to reinstate the Shetland brand for the $21^{\text {st }}$ century. Externally it must persuade the world to buy what Shetland offers. And internally it must inspire the people of Shetland to unify behind that offer and deliver its promise." The challenge for the brand, the report notes, is that "Shetland is in danger of being seen as a 'pre-modern society': simple, admirable but lost in a time warp." In response, the brand would position Shetland as "a small, clever country" (Lodge, 2003: 4-5; e.g. Shrimpton \& Pollett, 2000: 201).

Tellingly, Corporate Edge's fieldwork revealed that there might be local opposition to such positioning, with interviewees expressing "considerable anxiety about the ability and willingness of Shetlanders to deliver the quality promise," mainly as a result of Shetlanders' strong independent streak and complacency brought about by the oil boom (e.g., Highlands and Islands Enterprise, 2007: 8). The consultants argue that Shetlanders could be persuaded to take up the brand's quality promise if the brand reflected "the islands' character in a way that is recognized and approved of by Shetlanders." The consultants then identify three key elements of the islands' character (hereafter, 'brand coordinates'): Soul, Origins, and Fineness. To prove their point, they note that "these aspects of the spirit of the brand were strongly endorsed by the focus groups[,] which gives confidence that the brand, if it reflects these elements, will be resonant with Shetlanders" (Lodge, 2003: 5-6).

\section{Brand-Identity Conflict}

The content of the Corporate Edge report suggests that the consultants were uninformed concerning the cultural environment in which they began working. The consultants note that their proposed "brand template is true to Shetland but not yet unique to it, much of it being generic to other small, northern European communities, especially Orkney with whom Shetland shares many if not most of its cultural and product characteristics." The consultants therefore suggest that Shetland get a jump on the competition by "developing a fresh, new, distinctively Shetland visual style" faster than other communities can develop their own (Lodge, 2003: 8). The wording here is significant: Corporate Edge despaired of finding a unique Shetland brand, so it instead urged that this generic, small, northern European brand be given unique expression. Indeed, as Corporate Edge presents the idea, it 
is the expression that differentiates the brand from the generic. VisitShetland, the local tourist board, has followed this advice. A comparison between the 2008 tourist literatures of Orkney and Shetland shows that both archipelagos advertise the same sorts of activities and attractions but that Shetland does so with greater stylistic consistency.

Corporate Edge may well be spot on in its analysis of Shetland's historical cultural reality. What is lacking, however, is a sense of Shetlanders' cultural perception. Orkney is, indeed, the closest cultural historical analogue to Shetland, and it is understandable why one might assume that the two archipelagos share a cultural heritage. Surprisingly, most Orcadians and Shetlanders would disagree. For example, recent ethnographic research in Orkney has shown that most Orcadians feel strong emotional attachments to the archipelago's preNorse archaeological sites and view them as integral to and outstanding elements of Orcadian heritage (Lange, 2007: 27). Very similar archaeological sites are major tourist draws in Shetland as well, and both island groups' tourist boards market them accordingly. However, unlike Orcadians, most Shetlanders feel little or no connection with their islands' pre-Norse inhabitants. Shetland's pre-Norse peoples left their buildings and carved stones, and locals know that tourists come to Shetland to see such things, but a fair proportion of Shetlanders have never even visited their islands' major archaeological sites: The general feeling is that though these sites may be someone's heritage, they certainly are not the heritage of present-day Shetlanders.

In relation to this, Alastair Hamilton of the SIC's Economic Development Unit made the interesting suggestion to me that:

"I would not be at all surprised if more Orcadians [than Shetlanders] visited archaeological sites, but then nor would I be surprised to find that many, many more people in the UK associate Orkney with fine archaeology. Historic Scotland has several staffed sites in Orkney and they promote them and invest huge sums of money in them [...]. I suspect that Shetlanders, if they were subjected to Historic Scotland marketing and were offered elaborate, multi-million pound visitor centres such as that at Skara Brae, would engage with them just as Orcadians do" (Hamilton, 2008).

In other words, if kept up for long enough, marketing can pay off in terms of changing local perceptions of cultural heritage. Regardless of how it came about though, Orcadians' appreciation for their archipelago's pre-Norse inhabitants highlights Shetlanders' lack of a similar feeling.

To the contrary, Shetlanders feel strongly linked with their Scandinavian ancestors, whether these links are real or imagined. Unfortunately, while Orkney possesses impressive Old Norse heritage sites, like Kirkwall's St Magnus Cathedral and the ruins at the Brough of Birsay, there are no comparable sites in Shetland. ${ }^{2}$ Thus, the key markers of

\footnotetext{
${ }^{2}$ While Shetland does possess impressive multi-period sites with Old Norse elements, it is the pre-Norse elements that make these sites impressive. Thus, while both Orkney's Brough of Birsay and Shetland's Jarlshof are multi-period sites, the former is dominated by its Norse and the latter by its pre-Norse elements. An archaeologist might deem these two sites comparable, but from a local non-specialist's point of view, they hark back to different cultural inheritances.
} 
cultural heritage for Shetlanders are intangible rather than material: Shetlanders lack objects of built heritage that fill the cultural roles of Orkney's Skara Brae or Stenness.

What Shetlanders do have is a sense of connection with the islands' Norse past. Local character traits and habits - from the major, like good seamanship, to the minor, like taste in interior decorating - are liable to be attributed to Scandinavian influence. Shetland has grown rich on modernity, but Shetlanders are inclined to use this wealth to bolster traditional aspects of their culture. Shetland's pre-existing brand is, for better or for worse, centred on the Vikings. This backward-looking philosophy is, however, precisely what Corporate Edge's brand is meant to replace. The result is that, despite the consultants' stated desire for their brand to encapsulate the soul of Shetland, it fails completely to touch the souls of many Shetlanders.

For example, it is striking that the tourist materials produced by VisitShetland today include almost no pictures of Vikings even though the Viking image is Shetland's predominant cultural marker for both Shetlanders and outsiders. In the 2008 tourist guide and its accompanying interactive computer $\mathrm{CD}$, there are no photographs of the biggest event on the Shetland cultural calendar, Lerwick's Viking-themed Up-Helly-Aa fire festival. In the accompanying promotional DVD, Up-Helly-Aa makes a brief appearance at the very end. ${ }^{3}$ SIC officials involved in the branding process have offered me three possible explanations for the absence of Vikings in the promotional materials: 1) UpHelly-Aa is a local affair and has never been aimed at tourists; 2) the lack of Viking imagery might simply be unintentional; or 3) there is no need to promote Vikings since Up-Helly-Aa is really just one day out of the year and already attracts visitors to capacity.

The first two of these points may be answered with little trouble. As for the idea that UpHelly-Aa is not aimed at tourists, the same can be said of Shetland culture in general, yet the SIC has nevertheless decided - and this is not necessarily a bad thing - to brand local culture for international consumption. Regarding the second point, that the lack of Vikings might have been a mere oversight, most anyone who has spent a considerable amount of time in Shetland will know that this simply is not credible: A Shetland guidebook writer forgetting about the Vikings is analogous to an Egyptian guidebook writer forgetting about the Pyramids.

The third explanation - that Up-Helly-Aa need not be promoted since it already attracts as many tourists as it can handle - is rather more complex. Both Corporate Edge and the SIC are openly theoretically inclined toward Simon Anholt's branding philosophy (recently and concisely set forth in Anholt, 2008) and do not believe that the brand is a marketing instrument in itself: The idea is for the brand to send a message about Shetland and Shetlanders, not for it to advertise particular tourism or manufacturing products (Lodge, 2003: 13). From this point of view, the various aspects of Shetland identity have cross-over marketing applications: Thus, even though visitors may have difficulty gaining access to Shetland's famous fiddle music, tourists' awareness of the musical tradition represents value added to Shetland's archaeological sites and scenic destinations (Economic

\footnotetext{
${ }^{3}$ VisitShetland's website includes a section on Up-Helly-Aa, and its 'Cultural Life' section is illustrated with a photograph of 'baby Vikings' (VisitShetland, 2008a; 2008b). See, however, Note 5 below.
} 
Development Unit, 2008: 5). Furthermore, Corporate Edge's visual guide for the brand states explicitly that:

"The brand is all about communicating the best of Shetland present and future. Images of the past (and particularly in black and white) do not communicate the established brand values" (Corporate Edge, 2003: 8).

Images of Shetland's archaeological sites work fine in this context since these are places that tourists can actually visit and with which they can interact. While photographs of today's Up-Helly-Aa would not be in black and white, they would nonetheless communicate a message of rusticity - or worse, barbarity - that runs counter to the brand values.

If the Shetland brand is an attempt to combat the idea that Shetland is "pre-modern" and "lost in a time warp," what are we to do when the Shetlanders themselves disagree with this strategy? Shetland, as the SIC recognizes, has encountered difficulties adjusting its traditional, primary-sector industries to the new global economy. However, oil wealth has provided a buffer against the worst of these shocks, permitting the continued romanticization of the traditional Shetland lifestyle (Grydehøj, 2008). The echo-chamber type collaboration between the consultants and their employers produced a brand that is a poor reflection of actual Shetland identity. Whereas the SIC hired Corporate Edge to undertake brand development, Corporate Edge seems to have viewed its role as delivering a visual marketing strategy based on a brand that the SIC itself had already developed internally. Alastair Hamilton has admitted this much to me:

"It depends whether one casts a firm like Corporate Edge in the role of facilitator, simply helping people to expose a solution that's already latent, or in the role of reinventor, creating something new and, to a degree, artificial out of a (possibly selective) analysis of the character of a place. I actually believe that Corporate Edge saw themselves leaning more towards the first role, but I'm pretty sure that there were those involved in Shetland at the time who may have expected (and indeed pressed for) something closer to the second - and wanted it now! There is a whole issue here concerning the expectations that existed around the notion of the Shetland brand and how those expectations were managed. I don't think they were managed very well, which is partly why the whole process effectively ground to a halt for a while after Corporate Edge left the scene. However, I'm not at all sure that that was Corporate Edge's fault" (Hamilton, 2008).

The caveat here is that Corporate Edge's idea of the already-latent solution seems to have been based not on reality but on the SIC's prior attempts at internal brand development.

In this sense, Corporate Edge provided intellectual justification for the SIC's broadlymodernizing tendencies. For example, Corporate Edge's visual style guide justifies the Shetland brand's impressive layout scheme as a matter of actual culture by showing that the scheme is based on Shetland knitting patterns. This is despite the fact that the knitting allusion is so subtle that virtually no one would notice it were it not brought to his or her 
attention. The allusion seems to be for internal use only.

Since the new brand is not merely progressive but is intended to combat stereotypes about Shetland, it comes into direct conflict with the pre-existing, traditional brand and the people who promote it. Whether or not it is true that pre-modernity necessarily hampers attempts to sell products, bring in investment, draw tourists, and attract new inhabitants, some elements of Shetland identity, when given expression, almost certainly have adverse affects on Shetland's international reputation.

Although Shetlanders feel strong connections with the Old Norse and, to an extent, with present-day Norwegians, they predominantly see themselves simply as Shetlanders, as a nation or folk of their own. This conception attained its present form in the late 1800s when National Romanticism informed a reaction against perceived Scottish domination of Shetland. Shetland's ideology is postcolonial, and outsiders - particularly Scots - are still often viewed with suspicion. In the Romantic conception, Medieval Shetland had been a proud, self-sufficient community until the Scots took over, and more recently, North Sea oil - often viewed as Shetland's oil - has been exploited by the UK. Indeed, the Scottish National Party, which is currently governing in Edinburgh's devolved parliament, is often seen locally as attempting to 'steal' Shetland's oil wealth (e.g. Bartmann, 2000: 43). These beliefs might not be entirely accurate, but they are prevalent, and they form the backdrop for much of Shetland's cultural scenery, with local and foreign traditions being constantly contrasted in the public sphere. Nor has the SIC ignored the issue of how tourists might react to negative Shetland attributes: Neil Henderson, Principal Marketing Officer at the Economic Development Unit, has studied the effects of negative publicity arising from xenophobic comments that the Guizer Jarl, or Viking chief, directed at the national media at the 2005 Up-Helly-Aa (Henderson, 2005: ch. 6). These particular comments were just as exceptional as they were exceptionable but only because they were made in public by a public figure; the underlying sentiments are commonly held and discussed in Shetland.

The Shetland brand commissioned by the SIC and produced by Corporate Edge seems less like an attempt to counter misconceptions than it does like an attempt by a group of modernizers to reform Shetland identity from above, bringing it in line with perceived overseas demand (e.g. Chambers, 2000: 13). In response to my question as to whether the promoted Shetland brand is reconcilable with the pre-existing brand, Neil Henderson, replying on behalf of the SIC, said that "it is unnecessary to reconcile these. The brand project primarily had economic interests and the future development needs of Shetland at heart and thus sought to achieve these objectives" (Henderson, 2008a). There are serious doubts as to whether the officially-promoted brand can achieve even these limited objectives.

Central to Corporate Edge's proposal was the idea of elevating the Shetland brand by careful use of a logo in the marketing of quality-controlled local products. The goal posts have, however, shifted over time: SIC policy is now that "the logo and style are best reserved for generic promotions about Shetland as distinct from application to individual products." The SIC no longer wants local producers to use a Shetland quality mark; today, companies are seen as adhering to the brand if they embed the rather abstract "brand values 
in their products and service" (Economic Development Unit, 2008: 9). Indeed, at the moment, only material produced by VisitShetland bears the logo (see Figure 1).

Figure 1: Shetland Logo
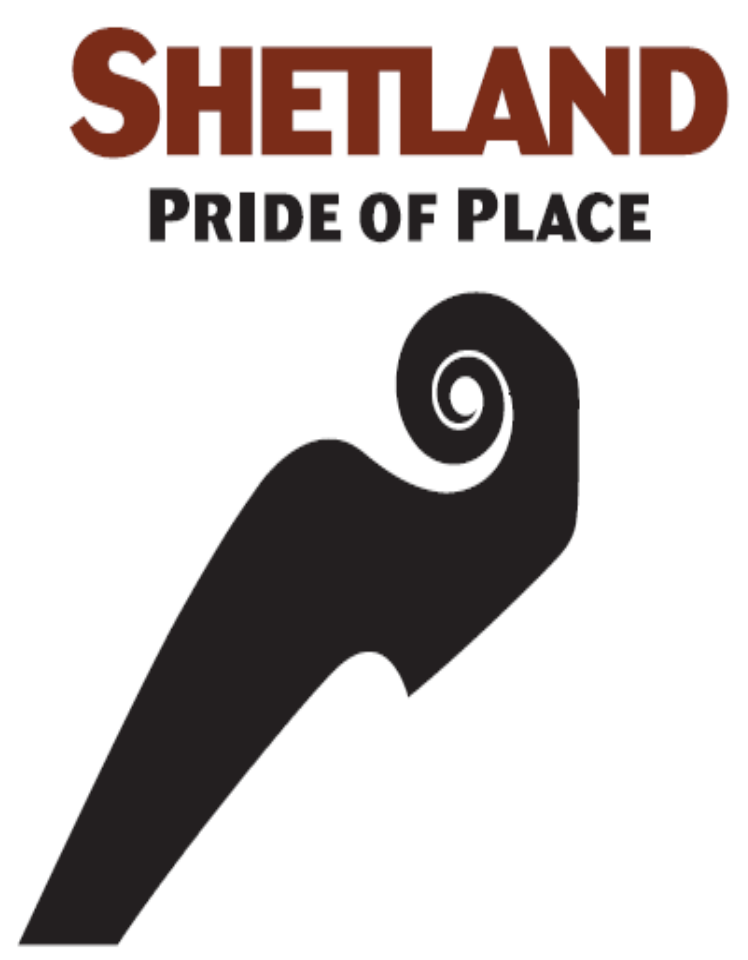

The reasons for this development are complex and are partially the result of EU restrictions on promotion of the brand (Henderson, 2008b). Additionally, a number of individuals involved in the brand development process have informed me that the branding project was underfunded from the start, which suggests that Corporate Edge's quality mark proposal was, at least in part, rejected due to a lack of resources for advertising the new brand to Shetlanders and for setting up a quality control body. It is worth considering though that the follow up to the consultancy's work might have been better funded had the new brand been well received locally: Despite the brand's success among outsiders at "official presentations," it has met with criticism and indignation on the home front. To a degree, this poor reaction can be attributed to some people failing to recognize the breadth of Corporate Edge's recommendations and believing that the consultancy had received its $€ 160,000$ fee solely for designing the Shetland logo. However, considering that the brand does not reflect the reality on the ground in Shetland, it is somewhat disingenuous that the SIC explains the brand's incomplete success as the result of a simple misunderstanding (Henderson, 2005: ch. 3).

Research by Neil Henderson, who was a key SIC figure in the branding process, suggests that visitors to Shetland are impressed by VisitShetland's post-branding promotional literature and feel that the brand is a valid reflection of the Shetland experience. Henderson's findings are very plausible, but they also reveal a gulf between the perceptions of tourists and Shetlanders. At the same time as Henderson is discovering that visitors are inspired by the brand and happy with the products and services provided by the public sector, he consistently records results that point to visitors being somewhat dissatisfied with the range and quality of products and services provided by the private sector, from access to traditional music, to quality of food in restaurants, to standards of accommodation facilities (Henderson, 2005: ch. 6). 
It is necessary to point out here that Corporate Edge's brand is not averse to 'tradition' in general. After all, 'Origins' is one of the brand coordinates. For example, Shetland knitting is symbolized in the brand's layout scheme, and the Shetland fiddle tradition is the most obvious inspiration for the brand's logo. I do not mean to suggest that Shetlanders note the lack of Vikings in tourist booklets and flatly reject the brand as a result; indeed, public rejection of the brand preceded its use in tourist materials. Rather, I suggest that the lack of Vikings - Shetland's most potent and distinctive symbol - is just an obvious proof of the artificial, externally-determined nature of the brand, and it is the basic disconnect between the brand and the branded that has prevented a more enthusiastic reception locally.

\section{Top-Down Place Branding}

Although the SIC is adamant that "it has never been the intention to 'bully conformance' to the brand" (Henderson, 2007), many of Neil Henderson's thoughts on place branding are underpinned by corporate branding theories that assume top-down control and enforced conformity (Henderson, 2005: ch. 3), despite the difficulties with translating experience from one type of branding to another (Frost, 2004). Henderson is aware of this, and he notes Nigel Morgan's assertion that place branding is "a political act," stating that a wellmanaged "place branding exercise can create a renewed purpose and identity for the inhabitants of a place and in effect create a summary for what a place stands for." In his subsequent analysis of the Shetland brand, Henderson cites Creenagh Lodge, the Corporate Edge consultant who led the Shetland project, to propose that:

"[A] place brand thus represents more than a superficial collection of icons and imagery but instead provides evidence of the collective will of an area to offer and deliver a competitive and attractive proposition" (Henderson, 2005: ch. 3).

In Shetland the brand developers made no clear distinction between marketing for outsiders and changing local identity. This may be compared with the idea behind the 2005 re-branding of Malta:

"The overall aim of the Internal Branding campaign is to ensure that eventually, the core values of the Malta brand are adopted by each and every citizen of these islands. We need to have 400,000 brand managers if we want to be truly ahead of our competitors. Experience shows that a strong brand is successfully developed from within, by adopting the core values of the brand into our lifestyles" (Malta Tourism Authority, 2005).

The brand development consultants have distilled and amplified the pre-existing conceptions of the SIC (rather than those of Shetlanders as a whole), and the SIC's own theoretical foundation, as exemplified by Henderson's work, is informed by traditional product marketing strategies and Simon Anholt's branding philosophy. 


\section{A. Grydehøj}

Corporate Edge's research into the pre-existing Shetland brand seems to have been inadequate. Had the consultants widened their focus groups, spoken with more than just "key people," and undertaken open-ended ethnographic fieldwork, they would have had little difficulty finding out that modernizing Shetland identity would be no easy task: My own fieldwork shows that simply asking most Shetlanders to define Shetland identity prompts talk about the importance of the islands' Old Norse heritage and Shetlanders' distrust of Scots. Nevertheless, as we shall see in the next section, flawed research methodology is a part of a deeper problem with Corporate Edge's approach to branding. Corporate Edge's inadequate fieldwork gave the consultancy - and by extension, the SIC an excuse for ignoring absolutely vital markers of Shetland identity. Like the knitting patterns in the layout scheme, this research seems to have been intended for internal justification only.

Corporate Edge never made a genuine attempt to get to grips with Shetland's pre-existing brand because the pre-existing brand had little connection with the consultancy's own aims. Instead of the official Shetland brand offering space for compromise and dialogue between the modernizers and the traditionalists, it whole-heartedly took the side of the former, which ultimately seems to have done both camps a disservice. With this in mind, it is little wonder that the brand was so poorly received by locals.

\section{Many Islands, Few Brands}

While VisitShetland's promotional literature displays Corporate Edge's marketing acumen, it is noteworthy that Corporate Edge's work on branding the island of Jersey has produced very similar results. Shetland's three brand coordinates are 'Soul, Origins, and Fineness'; Jersey's are 'Generous, Independent, and Cultivated'. The Shetland brand's core idea is that Shetland offers "a rich, rare quality experience" (Lodge, 2003: 7); Jersey's core idea is that "Jersey is life enriching" (Corporate Edge Branding, 2008). These characteristics are very abstract, but then again, they are bound to be: Corporate Edge views Shetland's brand template as "generic to other small, northern European communities" (Lodge, 2003: 8).

There can be little doubt that Corporate Edge has given up on creating place brands that are true to their host communities when the consultancy has managed to give more or less identical brands to places as different from one another as Jersey and Shetland. 'Small, northern European community' is not, after all, a terribly specific identity. Indeed, one suspects that the only relevant word in that title is 'northern': Neither Shetland nor Jersey are sub-tropical mass tourism destinations providing 'the three Ss' (Sun, Sea, and Sand), on which large-scale, international, island tourism frequently depends. Jersey, for example, is in the position of a number of Northern European islands (like Guernsey, Isle of Man, Scilly Isles, and Isle of Wight in Britain and Gotland, Bornholm, and Åland in the Baltic) that have experienced relative declines in domestic tourism as a result of increasinglyaffordable air travel to climatically-superior mass tourism destinations in the Mediterranean (Baum et al., 2000: 214). At the same time as many Mediterranean resort communities attempt to develop more diverse tourist economies, with focus on cultural/upmarket tourism and differentiation from other destinations (Selänniemi, 2001), 
cold-water island destinations may be moving in the opposite direction, toward greater conformity of tourism product.

I write in such a general sense because Corporate Edge is not the only brand developer to buy into a cold-water island generic. Corporate Edge's Shetland and Jersey brands are clearly meant to be viewed in opposition and as alternatives to the mass tourism generic brand, yet despite the consultancy's claims that its brands communicate the locations' unique qualities, all they do is place the islands in a second category of undifferentiated destinations. These brands are based not on the three Ss but on brand coordinates that might - at the risk of sounding somewhat glib - be characterized as 'the three Fs' ('Fresh, Friendly, and Futuristic'), which, in practice, really add up to a core idea of "Island $X$ is unique". This is complicated, however, by the fact that while three-S tourism products have traditionally been sold in a more or less undifferentiated manner by large-scale charter tour firms (Sastre \& Benito, 2001), many of Northern Europe's cold-water islands have based their very brands on differentiation as an end in itself, which is a problematic strategy when most such islands try to differentiate themselves in precisely the same ways.

Thus, cold-water islands that embrace the three-F ethos tend to produce tourism materials that bluntly assert a destination's uniqueness. For example, consider the following excerpts from 2008 titles and section titles in promotional booklets put out by Northern European insular tourist boards: VisitShetland's primary tourism booklet is entitled, 'Shetland: Get a World Away' (VisitShetland, 2008c). This may be compared with the Isle of Man's 'Set Yourself Free' booklet, which uses the word 'unique' twice on its first page of text (Department of Tourism and Leisure, 2008). In a similar vein, there is the booklet title, 'Bornholm- A World of its Own: Denmark's Only Rocky Island...' (Sonne, 2008). This booklet spreads over its first two pages the section title, "Everyone needs a bit of Bornholm," a strategy that is closely mirrored in Shetland's "The Wild Islands with a Warm Welcome: Something for Everyone" and Jersey's "Welcome to Jersey: Something for Everyone" (Visit Shetland, 2008c: 4 and Jersey Tourism and Jersey Hospitality Association, 2008: 1). The 'Orkney: Irresistible Islands' booklet, meanwhile, states much the same thing but ends all debate on the subject by, essentially, claiming magical powers: "The Orkney Islands are truly irresistible. [...] The 70 islands that make up our archipelago offer every kind of enchantment" (McLean, 2008: 1).

Most striking, however, is the 'Outer Hebrides: Beautifully Different' booklet, which takes the 'uniqueness' core idea strategy to its logical extreme by using the word 'different' in every one of its section titles (these being, "Different Hospitality", "Different Outlook", "Different Legends", "Different Cuisine", "Different Atmosphere", "Different Nature", "Different Activities", "Different Culture", "Different Scenery", "Different Traditions", "Different Pursuits", and "Different People") (VisitHebrides, 2008). It no longer appears quite so special to "get a world away" when there are so many little worlds out there.

Although these promotional booklets vary widely in terms of the professionalism of their colour and layout schemes, most of them express the same three-F brand values. ${ }^{4}$ It would

\footnotetext{
${ }^{4}$ Outer Hebrides is the exception. This destination's guide booklet opts purely for 'Fresh' and 'Friendly', leaving out 'Futuristic'. The potential effectiveness of this strategy is, in any case, overshadowed by the
} 


\section{A. Grydehøj}

be unwise to brush this off as 'mere tourism marketing' since many locations seem to use their tourism booklets for general place marketing, with the Isle of Man guide going so far as to include a section on reasons to move to Man (Department of Tourism and Leisure, 2008: 46-49).

It is not that these islands are truly all alike. For example, idyllic, wooded Bornholm has little in common with windswept, treeless Shetland in terms of archaeological and natural attractions. Even more glaringly, Shetland's population density of 15 inhabitants per square kilometre is very much lower than Jersey's population density of 783 per square kilometre; the difference in urbanization between the two locations is extreme.

Even more urbanized than Jersey, however, is the tiny, Mediterranean island-state of Malta, with a population density of 1,668 persons per square kilometre. Malta has traditionally been a three-S destination for mass tourism, but like many of its Mediterranean neighbours, it has begun exploring the possibilities for economic diversification. Unlike the SIC, which believed that Shetland's pre-existing brand was too old fashioned, those involved in the Maltese process felt that their pre-existing brand was overly centred on mass tourism; the intention was to develop a brand that could attract more upmarket, cultural tourists. Interestingly, even though the starting points were so diverse - underdeveloped versus overdeveloped, old-fashioned versus international hub, rural versus urban, cold water versus warm water - the end results of both efforts fit neatly into the three-F mould.

In June 2005, the Malta Tourism Authority, with the help of the Media Consulta consultancy, began an extensive brand development process. The result, revealed in December 2005, was a new, official Maltese brand based on the brand coordinates of 'Heritage, Diversity, and Hospitality' (Malta Tourism Authority, 2005), which are almost (though not wholly) interchangeable with Shetland's 'Soul, Origins, and Fineness' and Jersey's 'Generous, Independent, and Cultivated'. As others have noted, these brand coordinates "apply equally to any number of destination tourism brands, such as Croatia, or Cyprus, or Catalina" (Weekly B.S., 2006), not to mention the Northern European islands we have been considering here. Needless to say, the Maltese brand's core idea, "Enriching Your Life" is practically identical to 'Jersey is life enriching'.

\section{Advantages and Disadvantages to Generic Island Branding}

What is perhaps most startling here is that even a sunny, sandy mass tourism destination like Malta has opted for the three-F generic strategy so prevalent in cold-water island branding. The three-S and three-F divide does not seem to run along North-South lines; the split between the generic brands is motivated by Mass Tourism versus Cultural/Upmarket Tourism intentions.

brand's single-minded devotion to its 'differentness' core idea and the bluntness of this idea's marketing execution. 
It may be worthwhile asking why it is the case that local authorities and brand development consultancies would want to create undifferentiated brands. The answer is clearer in terms of mass tourism destinations since charter tour firms, which have traditionally driven this branding process, benefit from the intense price competition that results from brand uniformity (Ioannides et al., 2001: 12). It is in some such destinations for example, Malta - that a struggle is emerging between competing promoted brands, one mass market-oriented and one cultural/upmarket-oriented. But why, when every island is unique, do cultural/upmarket destinations settle for a three-F approach?

One possibility is that brand developers opt for the generic because it carries a genuinelypowerful message. In an article concerning the interplay between branding and immigrant entrepreneurship on Prince Edward Island, Godfrey Baldacchino suggests that insular place brands can benefit from making use of a generic sense of 'the island allure.' However, Prince Edward Island, in common with most of the communities we have considered here, has tried to have it both ways, choosing to retain some elements of the pure 'island allure' (for example, "clean and unspoilt spaces ripe for nature based adventure and discovery") while downplaying or undercutting others (for example, traditional ways of life). Prince Edward Island's branding has emphasized not only 'tradition' but also 'smartness', 'cleverness', and technological innovation (Baldacchino, 2009). In other words, the general, pre-existing 'island allure' encompasses a pair of threeF elements: 'Fresh' and 'Friendly'. To these, the brand developers in question have added 'Futuristic'.

In light of this, Baldacchino asks:

"If an island is already deeply wedded to an existing, iconic image typically connected to some locally available species, craft or material with high levels of local input (such as Fair Isle sweaters, Guernsey cows, Shetland ponies, Texel sheep, Barbados rum ...), how does it connect with a more contemporary, dynamic, technologically oriented symbolism without forfeiting its existing baggage, when the latter is likely to have persisting and long-term benefits in terms of reputation, customer loyalty and international recognition?" (Baldacchino, 2009).

Baldacchino's findings suggest it is precisely these iconic brand elements and the "quality of life issues" they radiate that might be most attractive to new residents, even when these new residents are working in high-tech sectors (ibid.). In relation to this and as regards tourism, Baldacchino has previously argued that 'Ice, Isolation, and Indigenous People' (a three-I approach) may have the potential to offer a sustainable basis for cold-water island economic progress (Baldacchino, 2006).

Thus, efforts to modernize traditional island brands - along the lines of Corporate Edge positioning Shetland as "a small, clever country" (Lodge, 2003: 4-5) - for the sake of outsiders may be counterproductive since they undercut the traditional brand imagery that has the power to draw investment and innovation from urban centres to the periphery. This may appear counterintuitive, so it is unsurprising that inadequate fieldwork could cause some brand developers to prioritize modernization. It does not, however, explain why so 
many brand developers have done so, why the cold-water island generic has shifted from Baldacchino's broad 'island allure' to the three Fs.

Michel Leseure straightforwardly suggests that generic branding is chosen because it takes little effort and holds out illusive rewards:

"Although the recourse to common island (e.g. scenery, beach, cruises) and non-island brand elements (such as walks, culture and dining) is easy and may be successful in trying to capture a variety of customers in the short run, this may create a longer term association of the island brand with an ordinary, mundane product. The tendency of islands to imitate the portfolio of offerings of their competitors increases this perception of island brands as being common. This risk can be worsened by the possibility of developing negative brand perception when traditional brand features, copied from competitors, are exaggerated in the definition of the brand" (Leseure, 2009).

These are very significant risks, and they are founded in 'attribute analysis', a strategy that, ideally, involves the listing of all possible island attributes $\left(\mathrm{ibid}\right.$.). ${ }^{5}$ In many of the islands we have considered, this strategy has led to confusion within a single brand as traditional and cutting-edge elements compete against one another (Baldacchino, 2009; Leseure, 2009). In the more established fields of product marketing, this 'something for everyone' approach has been largely dismissed, and non-market leaders are encouraged to undertake niche positioning rather than attempting to "cover all bets" (Ries \& Trout, 2001: 47-51; $60)$.

The Shetland strategy of Corporate Edge and the SIC was more nuanced in this regard than much of its competition: Because the official Shetland brand has left out the central aspect of the pre-existing, traditional Shetland brand, it is not subject to a similar degree of internal conflict. For precisely this same reason, however, the brand seems to have been rounded on by the local community and beset by external conflict.

\section{The Importance of Methodological Diversity}

The Shetland experience suggests that brands need to be developed out of their own cultural and geographical contexts. Whatever the context, some elements of local identity will prove problematic, and these need to be engaged rather than merely glossed over in favour of some universal marketing ideal. When the latter path is chosen, as was done for

\footnotetext{
${ }^{5}$ Leseure's analysis is based on island tourist board websites. This is interesting because printed and digital tourist materials tend to be quite different, even when published by the same organizations. For example, we have already noted that VisitShetland's website includes Vikings. In fact, VisitShetland's website includes just about everything, with much of it being listed on its front page. On the basis of the website alone, someone might make incorrect conclusions about the official brand. VisitShetland's printed materials show restraint and focus on Corporate Edge's brand ideals; but the freedom of being able to insert as much information as one likes into a limitless series of web pages seems to have made VisitShetland's online presence stray from the official line.
} 
Shetland, the destination and its products may gain value added in the abstract, but they risk losing value in the global market in which they operate. If the ideal for place branding aimed at any particular market is general and constant, then individual instances of place branding for a target market will ideally all be more or less standard, regardless of the reality on the ground. As we have seen, the result is that brand development often becomes at best the fine art of tinkering with nuances, with the strength of a brand being measurable by the quality of its style guide.

It is overly simplistic to blame the rise of the three-F generic in cultural and upmarket tourism destinations entirely on the prevalence of out-of-date product marketing mindsets among brand developers. Even if the official Shetland, Jersey, and Malta tourism brands are, in the end, aimed at a particular, upmarket consumer niche, their immediate targets are the island residents themselves. Unlike employees at a company, however, island populations cannot be forced to conform to a branding exercise; a board of directors can fire an off-message PR manager, but a county council has no means of getting rid of an off-message tour guide or shop owner.

Baldacchino suggests that island brand developers should "focus on 'quality of life' issues, since they appear to provide the appropriate combination that can lure entrepreneurs over and provide valid experience-based reasons for not going elsewhere"; though he also notes that "the trouble with this approach could be that the basics of 'island life' can be easily seen as more or less the same for the various cold water islands like PEI" (Baldacchino, 2009). It is in part because of this that the decision to exclude the most distinctive element of Shetland identity from the new Shetland brand seems so poorly judged. The Corporate Edge and SIC strategy made Shetland generic and sacrificed a portion of the location's 'island allure'. It is quite possible that Corporate Edge was merely fulfilling its brief by producing the sort of brand that the SIC wanted; but the existence of a flawed brief does not entirely excuse the development of a flawed product, particularly since the SIC outsourced the project to Corporate Edge precisely because it recognized the latter's expertise in the field.

If communities like Shetland, Jersey, and Orkney want to outpace their competitors and truly modernize their brands, rather than just attempt to place new brands on top of old ones, they will have to step back from the assumption of automatic local compliance (Baum et al., 2000: 225). An island authority wanting to revitalize its brand will have to be more attentive to the needs of the combined product-stakeholders, the community itself (Frost, 2004).

In order to listen to stakeholders, you first have to speak with them. Focus groups and surveys, both of which contribute vital information to cultural and market analysis, should be complimented by ethnographic fieldwork, time consuming though it may be. Simply speaking with the local community may not, however, be sufficient: Sue Lewis argues, with respect to the Isle of Man's 'Freedom to Flourish' branding campaign, that the brand developers undertook many qualitative interviews; yet they still produced a brand that many of the interviewees feel is a poor reflection of Man and Manx culture (Lewis, 2008). If ethnographic research conflicts with brand developers' assumptions, it is, perhaps, wiser 


\section{A. Grydehøj}

in the long run to go with the weight of local opinion - thus producing a sense of community ownership in the project - than to use the research to highlight the ways in which the local community needs to be reformed.

Just as folklorists and cultural anthropologists often reduce the practical value of their work by focusing exclusively on statistically-irrelevant methodologies, place branding academics and practitioners have at times produced research that, on account of its statistical relevance, deceptively appears to be more accurate a reflection of community and consumer sentiment than is actually the case. For example, in their seminal National Image \& Competitive Advantage, Jaffe and Nebenzahl (2006) cite just a handful of studies that could be considered ethnographic. Correct though many of the authors' insights may be, these are built on an incomplete methodological foundation, a disciplinary flaw that calls into question the evidential basis for their conclusions. Methodological diversity and improved sharing of knowledge between the various fields within the Humanities and the Social Sciences are vital if researchers are to aim for a fuller understanding of culture and community.

As in the case of Shetland's brand development process, the trick is just to get people talking.

\section{Acknowledgements}

This article is based on 'Brand-Identity Conflict in Shetland', a paper I presented at the $2^{\text {nd }}$ Annual Åland Institute for Comparative Island Studies (AICIS) conference in Mariehamn, Åland in June 2008. I would like thank the staff at the Shetland Islands Council (SIC), particularly Neil Henderson and Alastair Hamilton at the Economic Development Unit, for their assistance with answering my questions and placing materials relating to Shetland's brand development at my disposal. I would also like to thank the Shetlanders with whom I conducted interviews as part of an ongoing ethnological research project with the Elphinstone Institute at the University of Aberdeen. Finally, I would like to thank Ian Russell and Iason Koufodontis for their ideas concerning the branding of Shetland. The conclusions presented here are my own and do not necessarily reflect the stance of the SIC.

\section{References}

Anholt, S. (2008) 'Place Branding: Is It Marketing, or Isn't It?', Place Branding and Public Diplomacy, Vol. 4, No. 1, February, 1-6.

Baldacchino, G. (2006) 'Warm versus Cold Water Island Tourism: A Review of Policy Implications', Island Studies Journal, Vol. 1, No. 1, pp. 183-200.

Baldacchino, G. (2009) 'Island Brands and 'The Island' as a Brand: Insights from Immigrant Entrepreneurs on Prince Edward Island', International Journal of Entrepreneurship and Small Business, Vol. 9, No. 4, forthcoming. 
Bartmann, B. (2000) 'Patterns of Localism in a Changing Global System' in G. Baldacchino \& D. Milne (eds.) Lessons from the Political Economy of Small Islands: The Resourcefulness of Jurisdiction, Basingstoke, Macmillan, pp. 38-55.

Baum, T.G., Hagen-Grant, L., Jolliffe, L., Lambert, S. and Sigurjonsson, B. (2000) 'Tourism and Cold Water Islands in the North Atlantic' in G. Baldacchino \& D. Milne (eds.) Lessons from the Political Economy of Small Islands: The Resourcefulness of Jurisdiction, Basingstoke, Macmillan, pp. 214-229.

Chambers. E. (2000) Native Tours: The Anthropology of Travel and Tourism, Prospect Heights, Waveland.

Cohen, B.J. (1983) Norse Imagery in Shetland: An Historical Study of Intellectuals and Their Use of the Past in the Construction of Shetland's Identity, with Particular Reference to the Period 1800-1914, University of Manchester PhD thesis.

Crawford, B. E. (1987) Scandinavian Scotland: Scotland in the Early Middle Ages: Volume 2, Avon, Leicester University Press.

Corporate Edge (2003) 'Shetland Brand Guide', Visual Guide created for Economic Development Unit, Shetland Islands Council, April.

Corporate Edge Branding (2008) 'Jersey: Case Study', Corporate Edge Branding, www.corporateedgebranding.com.

Department of Tourism and Leisure (2008) 'Set Yourself Free', Ramsey (Isle of Man): Lily.

Depraetere, C. (2008) 'The Challenge of Nissology: A Global Outlook on the World Archipelago, Part 1: Scene Setting the World Archipelago', Island Studies Journal, Vol. 3, No. 1, pp. 3-16.

Dundes, A. (1965) 'The Study of Folklore in Literature and Culture: Identification and Interpretation', The Journal of American Folklore, Vol. 78, No. 308, pp. 136-142.

Economic Development Unit (2008) 'A Marketing Strategy for Shetland, 2008-2011: Draft', economic development strategy document, April.

Frost, R. (2004) 'Mapping a Country's Future', Brandchannel.com, 19 April, www.brandchannel.com/features_effect.asp?pf_id=206.

Fry, G., Chantavanich, S., and Chantavanich A. (1981) 'Merging Quantitative and Qualitative Research Techniques: Toward a New Research Paradigm', Anthropology \& Education Quarterly, Vol. 12, No. 2, pp. 145-158. 


\section{A. Grydehøj}

Grydehøj, A. (2008) 'Nothing but a Shepherd and His Dog: Social and Economic Effects of Depopulation in Fetlar, Shetland', Shima: The International Journal of Research into Island Cultures, Vol. 2, No. 2, pp. 56-72.

Hamilton, A. (2008) E-mail sent to Adam Grydehøj on behalf of the SIC, 20 August.

Henderson, N. (2005) 'Place Branding: Linking the Shetland Brand to a Marketing Strategy for Shetland Tourism', Robert Gordon University MA dissertation, October.

Henderson, N. (2008a) E-mail sent to Adam Grydehøj on behalf of the SIC, 24 April.

Henderson, N. (2008b) E-mail sent to Adam Grydehøj on behalf of the SIC, 19 May.

Highlands and Islands Enterprise (2007) Shetland: Economic Update, Highland and Island Enterprise, April, www.hie.co.uk/HIE-economic-reports-2007/Economic-report-Shetland2007.pdf.

Ioannides, D., Apostolopoulos, Y., \& Sonmez, S. (2001) 'Searching for Sustainable Tourism Development in the Insular Mediterranean' in D. Ioannides, Y. Apostolopoulos \& S. Sonmez (eds.) Mediterranean Islands and Sustainable Tourism Development: Practises, Management and Policies, Island Studies Series, London and New York: Continuum, pp. 3-22.

Jersey Tourism and Jersey Hospitality Association (2008) 'Destination Jersey', St Helier, Jersey, Jersey Tourism and Jersey Hospitality Association.

Lange, M.A. (2007) The Norwegian Scots: An Anthropological Interpretation of VikingScottish Identity in the Orkney Islands, Lewiston NY, Edwin Mellen.

Leseure, M. (2009) 'Exploitation versus Exploration in Island Economies: A Brand Diagnostic Perspective', International Journal of Entrepreneurship \& Small Business, Vol. 9 , No. 4, forthcoming.

Lewis, S. (2008) A Land of Possibility? 'Manx Cultural Identity and the Campaign for a Commonwealth in the Isle of Man', presentation given at the American Folklore Society's 2008 annual meeting, Louisville, Kentucky, 25 October.

Lodge, C. (2003) 'Project Selkie: The Recommended Brand Strategy for Shetland', Project report document, 5 June.

Malta Tourism Authority (2005) 'Branding Malta', Malta, Malta Tourism Authority, http://www.mta.com.mt/index.pl/branding_malta.

McLean, D. (2008) ‘Orkney: Irresistible Islands’, Kirkwall, Orkney, VisitOrkney. 
PoolHaddock (pseudonymous) (2006) 'Shetland: We Believe Anything', Parody logo, Shetlink, $12 \quad$ November. www.shetlink.com/forum/viewtopic.php?t $=1745 \&$ postdays $=0$ \&postorder $=$ asc \&start $=25 \& \mathrm{~s}$ id=a5c485b415dacd0c0e8afc88775cf3bd.

Reference Economic Consultants (2006) 'Opportunities for the Future of the Shetland Economy', Economic development review document, February, www.shetland.gov.uk/council/documents.asp.

Robertson, C. (2006) 'Shetland: Pride of Plaice', Parody logo, Shetlink, 10 October, www.shetlink.com/forum/viewtopic.php?t=1528.

Salamone, F.A. (1979) 'Epistemological Implications of Fieldwork and their Consequences', American Anthropologist, New Series, Vol. 81, No. 1, pp. 46-60.

Sastre, F. \& Benito, I. (2001) 'The Role of Transnational Tour Operators in the Development of Mediterranean Island Tourism' in D. Ioannides, Y. Apostolopoulos \& S. Sonmez (eds.) Mediterranean Islands and Sustainable Tourism Development: Practises, Management and Policies, Island Studies Series. London, Continuum, pp. 69-86.

Selänniemi, T. (2001) 'Trapped by the Image: The Implications of Cultural Tourism in the Insular Mediterranean' in D. Ioannides, Y. Apostolopoulos \& S. Sonmez (eds.) Mediterranean Islands and Sustainable Tourism Development: Practices, Management and Policies, Island Studies Series. London and New York, Continuum, pp. 108-123.

Shetland Islands Council (2007a) 'Shetland and Oil', Energy from the Edge, www.energyfromtheedge.com/shetland-and-oil.

Shetland Islands Council (2007b) Shetland in Statistics: 2007, No. 34, Lerwick, UK, Shetland Islands Council, Economic Development Unit, www.shetland.gov.uk/council/documents.asp.

Shetland Local Economic Forum (2002) 'Shetland 2012', Economic Development Strategy Document, Highlands and Islands Enterprise, September, www.hie.co.uk/SHElef-economic-strategy.pdf.

Shrimpton, M. \& Pollett, C. (2000) 'Small Places, Big Ideas: Exporting North Atlantic Expertise' in G. Baldacchino \& D. Milne (eds.) Lessons from the Political Economy of Small Islands: The Resourcefulness of Jurisdiction, Basingstoke, Macmillan, pp. 193-213.

Sonne, C. (2008) 'Bornholm: A World of Its Own. Denmark's Only Rocky Island...', Rønne, Bornholm, Denmark, Destination Bornholm.

Søderberg, A.M. (2008) Introductory Remarks at $2^{\text {nd }}$ Annual AICIS Conference, Mariehamn, Åland, Åland Institute for Comparative Island Studies, June. 


\section{A. Grydehøj}

VisitHebrides (2008) 'Outer Hebrides: Beautifully Different', Stornoway, Lewis, VisitHebrides.

VisitShetland (2008a) 'Major Events: Up Helly Aa', VisitShetland, www.visitshetland.com/major-events/up-helly-aa.

VisitShetland (2008b) 'Attractions and Activities: Cultural', VisitShetland, www.visitshetland.com/attractions-and-activities/cultural.

VisitShetland (2008c) 'Shetland: Get a World Away', Lerwick, Shetland, VisitShetland.

Wawn, A. (2000) The Vikings and the Victorians: Inventing the Old North in Nineteenthcentury Britain, Cambridge, D.S. Brewer.

Weekly B.S. (2006) 'Malta Brand Effort is Advertising in Disguise', Whisper, 5 January, www.whisperbrand.com/blog/2006/01/malta-brand-effort-is-advertising-in-disguise.

Wiggen, G. (2002) Norns død, iscer skolens rolle: Kommentarer til en disputt om nedgangen for det nordiske språket på Orknøyene og Shetland [Norn's Death, with Emphasis on the Role of Schools: Commentary on a Dispute Concerning the Decline of the Nordic Language in Orkney and Shetland], Det Norske Videnskaps-Akademi: II. Hist.Filos. Klasse Skrifter og avhandlinger, No. 1, Oslo, Novus. 